\title{
In Vivo Imaging of Reactive Oxygen Species Specifically Associated with Thioflavine S-Positive Amyloid Plaques by Multiphoton Microscopy
}

\author{
Megan E. McLellan, Stephen T. Kajdasz, Bradley T. Hyman, and Brian J. Bacskai \\ Massachusetts General Hospital, Department of Neurology/Alzheimer’s Disease Research Laboratory, Charlestown, Massachusetts 02129
}

\begin{abstract}
Amyloid- $\beta$, the primary constituent of senile plaques in Alzheimer's disease, is hypothesized to cause neuronal damage and cognitive failure, but the mechanisms are unknown. Using multiphoton imaging, we show a direct association between amyloid- $\beta$ deposits and free radical production in vivo in live, transgenic mouse models of Alzheimer's disease and in analogous ex vivo experiments in human Alzheimer tissue. We applied two fluorogenic compounds, which become fluorescent only after oxidation, before imaging with a near infrared laser. We observed fluorescence associated with dense core plaques, but not diffuse plaques, as determined by subsequent addition of thioflavine $S$ and immunohistochemistry for amyloid- $\beta$. Systemic administration of $N$-tert-butyl- $\alpha$-phenylnitrone, a free radical spin trap, greatly reduced oxidation of the probes. These data show directly that a subset of amyloid plaques produces free radicals in living, Alzheimer's models and in human Alzheimer tissue. Antioxidant therapy neutralizes these highly reactive molecules and may therefore be of therapeutic value in Alzheimer's disease.
\end{abstract}

Key words: amyloid- $\beta$; free radicals; multiphoton; in vivo imaging; oxidative stress; Alzheimer's disease

\section{Introduction}

Senile plaques containing amyloid- $\beta$ are a prominent histopathological feature of Alzheimer's disease (AD). Amyloid- $\beta$ deposits can be quite dense with a $\beta$-pleated sheet conformation, leading to staining by dyes such as thioflavine $S$, or be present in diffuse, nonfibrillar deposits. In vitro studies show that synthetic amyloid- $\beta$ facilitates the formation of free radicals (Hensley et al., 1994 ), causing membrane lipid peroxidation and increased production of reactive oxygen species in cells in culture, resulting in toxic effects (Behl et al., 1994; Mattson and Goodman, 1995; Keller et al., 1997). Indirect markers of oxidative damage in postmortem studies of the brains of patients diagnosed with $\mathrm{AD}$ or in animal models of $\mathrm{AD}$ include changes in antioxidant enzymes (Pappolla et al., 1998; Leutner et al., 2000), advanced glycation end products (Wong et al., 2001), lipid peroxidation (Behl et al., 1994; Mark et al., 1997; Mattson et al., 1997; Montine et al., 1997; Sayre et al., 1997), free carbonyls (Hensley et al., 1995; Smith et al., 1996), and peroxynitration (Good et al., 1996; Smith et al., 1997). However, the role of plaques in generating free radicals is not certain, and evidence also supports alternative hypotheses regarding amyloid- $\beta$ and free radical generation. Some suggest that oxidative stress precedes amyloid- $\beta$ deposition (Yan et al., 1995; Nunomura et al., 2000; Pratico et al., 2001) or that amyloid- $\beta$ fibrils can act as free radical scavengers having super-

\footnotetext{
Received 0ct. 18, 2002; revised Jan. 2, 2003; accepted Jan. 7, 2003

This work was supported by National Institutes of Health Grant AG08487 and a Pioneer Award from the Alzheimer Association. We thank Drs. D. Schenk and D. Games (Elan Pharmaceuticals, South San Francisco, CA) for access to PDAPP mice. We thank B. Whalen for assistance with preliminary experiments. We thank the Massachusetts Alzheimer Disease Research Center Brain Bank (AG05134), Dr. E. T. Hedley-Whyte, director, for access to human brain tissue.

Correspondence should be addressed to Dr. Brian J. Bacskai, Massachusetts General Hospital, Department of Neurology/Alzheimer's Disease Research Laboratory, 114 Sixteenth Street, \#2750, Charlestown, MA 02129. E-mail: bbacskai@partners.org.

Copyright $\odot 2003$ Society for Neuroscience $\quad 0270-6474 / 03 / 232212-06 \$ 15.00 / 0$
}

oxide dismutase-like activity in vitro (Bush et al., 1999). Moreover, the role of amyloid-associated microglia in free radical production and subsequent oxidative damage is also uncertain, because activated microglia are frequently observed near compact (thioflavine S-positive) senile plaques in $\mathrm{AD}$, and microglia can generate and release free radicals (Colton et al., 1994; Kiprianova et al., 1997).

In the present study, we examined the free radical-producing properties of amyloid- $\beta$ in vivo in transgenic PDAPP and Tg2576 mice that develop senile plaques. We used a multiphoton imaging technique that provides real time imaging of fluorescent reporter molecules in living brain. 2', $7^{\prime}$-Dichlorodihydrofluorescein $\left(\mathrm{H}_{2} \mathrm{DCF}\right)$ forms the green fluorescent $2^{\prime}, 7^{\prime}$-dichlorofluorescein (DCF) after oxidation by reactive oxygen species (LeBel et al., 1992), and Amplex Red reagent (10-acetyl-3,7-dihydroxyphenoxazine) oxidizes to the red fluorescent resorufin in the presence of hydrogen peroxide (Zhou et al., 1997). We applied both probes topically to the brains of transgenic mice with significant amyloid plaque burdens and imaged through cranial windows with a lowenergy, near infrared laser to minimize the risk of light-induced oxidation. We observed activation of both probes by dense core (thioflavine S-positive) amyloid plaques, but not diffuse deposits, suggesting free radical oxidation in the vicinity of a subset of plaques. We also demonstrated, in an ex vivo system using human $\mathrm{AD}$ brain tissue, that thioflavine $\mathrm{S}$-positive plaques in $\mathrm{AD}$ are also sources of free radicals and that amyloid-associated microglia are not responsible for the oxidation of the probes in relation to the plaques. We provide further support that an oxidative process occurs in association with dense core plaques by inhibiting oxidation of the probes using a free radical spin trap, $\mathrm{N}$-tert-butyl$\alpha$-phenylnitrone (PBN). PBN has been shown to be very effective in reducing $A \beta$ toxicity in cell culture (Behl et al., 1994) and to improve age-related cognitive deficits in animal models (Carney 
et al., 1991; Socci et al., 1995). Thus, fibrillar A $\beta$ is a potent source of free radicals in a living system that can be targeted effectively with free radical scavenging molecules, supporting the use of antioxidant therapies in treatment of AD.

\section{Materials and Methods}

Animals and reagents. In vivo imaging was performed using multiphoton microscopy, as previously described (Christie et al., 2001), in homozygote PDAPP (Games et al., 1995) or Tg2576 (Hsiao et al., 1996) APPoverexpressing transgenic mice (aged 15-21 months; $n=4$ mice for each free radical indicator). A stock solution of $2^{\prime}, 7^{\prime}$-dichlorodihydrofluorescein diacetate (Molecular Probes, Eugene, OR) was prepared in dimethylsulfoxide (DMSO; $200 \mathrm{~mm}$ ). Acetyl groups were removed following standard protocol (Molecular Probes), and stock $\mathrm{H}_{2} \mathrm{DCF}$ was diluted to $200 \mu \mathrm{M}$ in PBS. Amplex Red reagent (10-acetyl-3,7-dihydroxyphenoxazine; Molecular Probes) stock solution was prepared in DMSO (20 mM) and diluted in PBS to $200 \mu \mathrm{M}$. Thioflavine S (Sigma, St. Louis, MO) was diluted to $0.01 \%$ in PBS. PBN (Sigma) was prepared at $100 \mathrm{~mm}$ in $20 \%$ DMSO in saline and injected at $300 \mathrm{mg} / \mathrm{kg}$. The anti-amyloid antibody used was 3D6 (Elan Pharmaceuticals, San Francisco, CA), conjugated to either fluorescein or Cy3 (Molecular Probes) at $20 \mu \mathrm{g} / \mathrm{ml}$ for immunohistochemistry on tissue sections. Avertin (tribromoethanol; Sigma) was the anesthetic used in all surgical procedures. For fluorescent angiograms, either Texas Red dextran (70,000 MW; Molecular Probes) or AK-Fluor $10 \%$ injection fluorescein (Akorn, Inc., Decatur, IL) was injected at $33 \mathrm{mg} / \mathrm{kg}$.

Surgical preparation and application of probes. Mice were anesthetized with an intraperitoneal injection of Avertin $(250 \mathrm{mg} / \mathrm{kg})$, with supplemental doses $(40 \mathrm{mg} / \mathrm{kg})$ as needed. Cranial windows were prepared 3-6 $\mathrm{d}$ before an experiment according to the previously described technique (Mathis et al., 2002). At the beginning of the experiment, the coverslip was removed from the skull, and the site was rinsed thoroughly with sterile saline. Either $\mathrm{H}_{2}$ DCF or Amplex Red reagent (both $200 \mu \mathrm{M}$ ) was applied to the cortex of the mouse, and the head was covered to protect from light for $\sim 30 \mathrm{~min}$. The site was then washed, and the coverslip was replaced. The animal was placed on a thermally regulated pad (Harvard Apparatus, Holliston, MA) until the glue was dry and the animal was ready to be imaged. In experiments using PBN, the animal was injected intraperitoneally with PBN $(300 \mathrm{mg} / \mathrm{kg})$ the night before imaging and again 15-20 min before imaging. $\mathrm{H}_{2}$ DCF $(200 \mu \mathrm{M})$ was prepared in a 100 mM solution of PBN and applied to the brain just as $\mathrm{H}_{2} \mathrm{DCF}$ and Amplex Red were applied in previous experiments. The animal was prepared for imaging as before.

Multiphoton imaging. Two-photon fluorescence was generated with 750 or $800 \mathrm{~nm}$ excitation from a mode-locked Ti:Sapphire laser (Tsunami; Spectra-Physics, Mountain View, CA), mounted on a commercially available multiphoton imaging system (Bio-Rad 1024ES; Bio-Rad, Hercules, CA). Custom-built external detectors containing three photomultiplier tubes (Hamamatsu Photonics, Bridgewater, NJ) collected emitted light in the range of 380-480 (thioflavine S), 500-540 (fitc-3D6 and DCF), and 560-650 nm (Cy3-3D6 and Amplex Red). Imaging was performed using the normal scan speed of the scanhead, and multiple Z-series' were collected at the following time points: before adding reagents to the brain; after adding Amplex Red, $\mathrm{H}_{2} \mathrm{DCF}$, or $\mathrm{H}_{2} \mathrm{DCF} / \mathrm{PBN}$; and again after adding thioflavine $\mathrm{S}$. The $\mathrm{z}$-series moved from the skull surface into the brain and used one or all of the following: a $20 \times$ water immersion objective $(615 \times 615 \mu \mathrm{m} ; z$-step, $5 \mu \mathrm{m}$; depth, $\approx 200 \mu \mathrm{m})$; a $60 \times$ water immersion objective $(205 \times 205 \mu \mathrm{m}$; $z$-step, $2 \mu \mathrm{m}$; depth, $\approx 150 \mu \mathrm{m})$; a $100 \times$ water immersion objective $(123 \times 123 \mu \mathrm{m}$; $z$-step, 1 $\mu \mathrm{m}$; depth, $\approx 100 \mu \mathrm{m}$ ). A UV arc lamp was used in remote areas of the brain to ensure that the nonfluorescent dyes were present, distributed throughout the brain, and responsive to oxidative activity. UV light excitation led to immediate and robust oxidation of both Amplex red and $\mathrm{H}_{2}$ DCF throughout the brain, demonstrating that the dyes were available, and emphasizing the utility of multiphoton imaging, which did not lead to measurable oxidation of the probes. After image collection, the animal was placed on the thermal pad until body temperature had returned to normal and the animal was fully conscious.
A

B

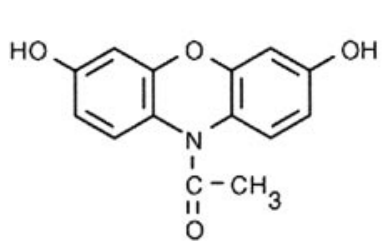

Amplex Red

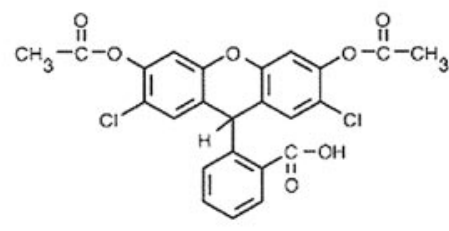

$\mathrm{H}_{2} \mathrm{DCF}$
Figure 1. Free radical indicators are chemically distinct. The structures and properties of the two fluorogenic indicators of oxidative stress, Amplex Red $(A)$ and $\mathrm{H}_{2} \mathrm{DCF}(B)$, are unique.

Ex vivo assays. Tissue sections of either PDAPP mouse brain $(n=3)$ or of temporal cortex and hippocampus of human $\mathrm{AD}$ or control tissue ( $n=3$; courtesy of the Massachusetts Alzheimer Disease Research Center Brain Bank) (Newell et al., 1999) were used for ex vivo assays. Assays were performed in both cryostat (lightly fixed in 100\% ethanol, $8 \mathrm{~min}$ ) and fixed (mouse tissue: paraformaldehyde, $24 \mathrm{hr}$ postmortem; human tissue: periodate-lysine-paraformaldehyde, $48 \mathrm{hr}$ postmortem) tissue sections with similar results. Mounted tissue was dehydrated, encircled with a hydrophobic PAP pen (Research Products International, Mount Prospect, IL), and rehydrated in PBS. Sections were then treated with Amplex Red (200 $\mu \mathrm{M}$ in PBS), $\mathrm{H}_{2}$ DCF (200 $\mu \mathrm{M}$ in PBS), or PBS alone for $\sim 30$ $\mathrm{min}$, covered to minimize light and air exposure. Slides were dipped quickly in PBS to rinse excess reagent, aqueously coverslipped, and imaged under the same conditions as in vivo imaging. Sections were washed overnight in PBS and reimaged. Thioflavine $S$ was then added for $15 \mathrm{~min}$, and fitc-3D6 (on Amplex Red-treated sections; 1:500 in NGS) or Cy33D6 (on $\mathrm{H}_{2}$ DCF-treated sections; 1:500 in NGS) for $1 \mathrm{hr}$. Slides were reimaged in the same locations as previously.

\section{Results}

We have previously developed the techniques to image senile plaques in the cortex of living animals using multiphoton microscopy and either in vivo histology (with thioflavine S or thiazine red) or in vivo immunohistochemistry (using fluorescently labeled anti-amyloid- $\beta$ antibodies) (Bacskai et al., 2001, 2002; Christie et al., 2001). To extend this approach to perform in vivo histochemistry for in vivo detection of free radicals, we took advantage of the availability of two small molecule, dependable markers of oxidative stress, both nonfluorescent unless oxidized by free radicals.

We first examined whether these direct indicators would detect any alterations in the transgenic mice using mulitphoton in vivo imaging. Multiphoton approaches are especially useful for these studies because the UV light or blue-green light used to detect $\mathrm{H}_{2} \mathrm{DCF}$ in traditional applications, such as confocal microscopy, rapidly oxidizes the probe, whereas the near infrared light used for multiphoton imaging does not lead to $\mathrm{H}_{2} \mathrm{DCF}$ or Amplex Red activation even after prolonged ( $>15 \mathrm{~min}$ ) exposure. The two fluorescent reporters are chemically distinct (Fig. 1). Amplex Red reagent is a very stable, nonfluorescent molecule that emits red fluorescence when oxidized specifically by hydrogen peroxide. When added in its reduced, colorless form directly to the cortex of a live PDAPP mouse, Amplex Red rapidly became fluorescent specifically and uniquely associated with structures that resemble senile plaques (Fig. $2 A$ ). We then added thioflavine $S$, a fluorescent histochemical marker of dense core senile plaques, and detected the resulting blue-green fluorescence in a second optical channel (Fig. 2C). Amplex Red-positive structures overlapped completely with thioflavine S-stained senile plaques and, occasionally, with amyloid angiopathy. In addition, these same plaques appeared to be associated with accumulation of 

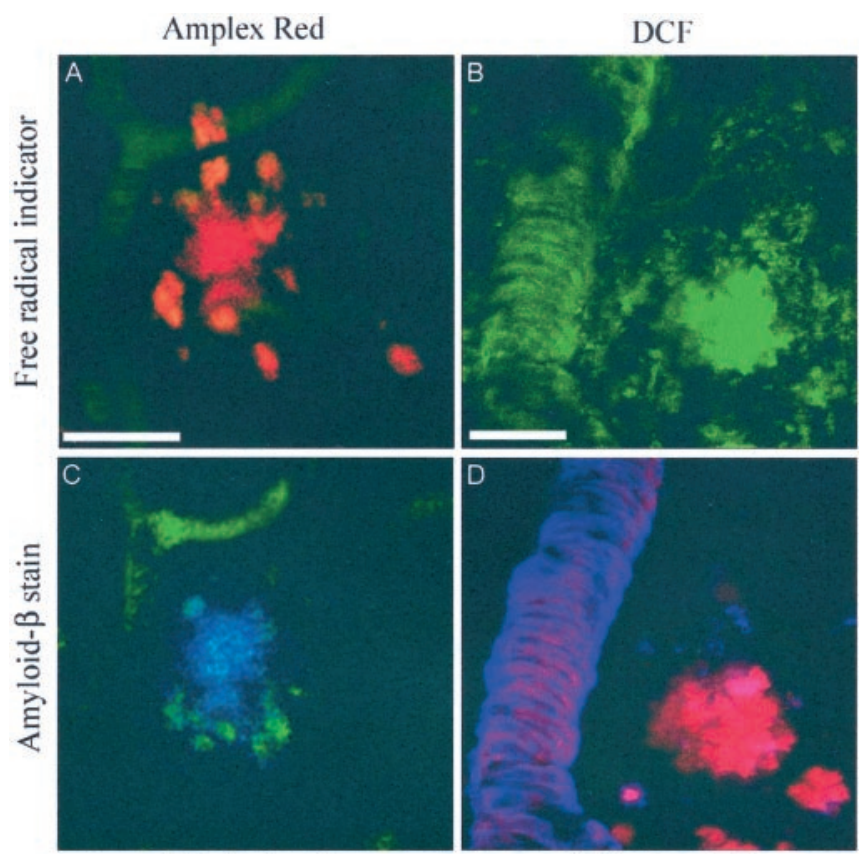

Thioflavine S

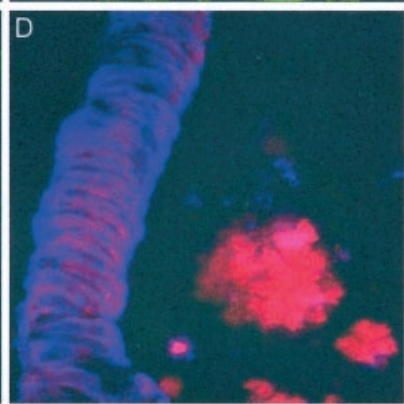

Thiazine Red

Figure 2. A subset of amyloid- $\beta$ plaques oxidizes free radical indicators in vivo. Dense core amyloid- $\beta$ plaques activate the fluorogenic free radical indicators Amplex Red $(A)$ and $\mathrm{H}_{2} D C F$ $(B)$ in vivo in live, PDAPP mouse cortex. Histochemical markers of dense core plaques, thioflavine $S(C)$ and thiazine red $(D)$, respectively, confirm these results. Vessel-associated amyloid angiopathy occasionally activated the probes $(B)$, confirmed here with thiazine red $(D)$. Autofluorescent lipofuscin was observed near plaques in multiple optical channels ( $A$, orange). Fluorescein-containing blood vessels used to map sites for reimaging are shown in green in $A$ and C. Scale bars: $A, C, 10 \mu \mathrm{m} ; B, D, 25 \mu \mathrm{m}$.

lipofuscin, an autofluorescent, endogenous product associated with local oxidative stress (Fig. $2 \mathrm{~A}$, orange signal). We confirmed these observations in a second strain of transgenic mice (i.e., experiments were performed in both Tg2576 and PDAPP animals) with identical results. Moreover, we confirmed the observations with an alternative reporter of free radicals, $\mathrm{H}_{2} \mathrm{DCF}$. Colorless, nonfluorescent $\mathrm{H}_{2}$ DCF converts to bright green fluorescent DCF in the presence of a number of reactive oxygen intermediates. DCF fluorescence (Fig. $2 B$ ) also associated specifically with dense core plaques (visualized by thiazine red; Fig. $2 D$ ) in transgenic mouse cortex. Thiazine red is comparable to thioflavine $\mathrm{S}$ as a histochemical marker of dense core plaques. In some images, we again observed DCF fluorescence associated with vessel-related amyloid angiopathy (Fig. $2 B, D$ ).

Neither Amplex Red nor $\mathrm{H}_{2} \mathrm{DCF}$ crosses cell membranes in adult brain tissue, suggesting that the observed fluorescence is caused by an extracellular oxidative or free radical source. We reasoned that a free radical scavenger might therefore be able to neutralize free radical production and prevent $\mathrm{H}_{2} \mathrm{DCF}$ oxidation. We administered PBN systemically via intraperitoneal injection $20 \mathrm{hr}$ and $15-20 \mathrm{~min}$ before imaging with $\mathrm{H}_{2}$ DCF and thioflavine S. After PBN administration, a dramatic decrease in DCF fluorescence was observed that was associated with dense core plaques that were visualized clearly with thioflavine $S$ (Fig. 3). Arrows in Figure $3 A$ designate thioflavine $S$-positive plaques, whereas in Figure $3 B$, arrows indicate where DCF-positive plaques are absent because of PBN treatment. We quantified the images by calculating the percent increase of DCF fluorescence in a plaque compared with its immediate surroundings. This revealed a highly statistically significant $40 \%$ change in DCF fluorescence
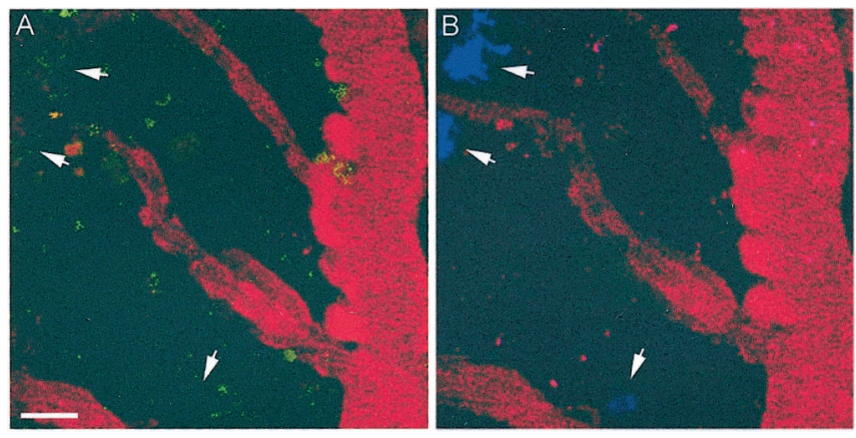

Figure 3. $\mathrm{PBN}$ can prevent plaque-associated oxidation in vivo. Systemic administration of a free radical spin trap, $\mathrm{PBN}$, prevents oxidation of $\mathrm{H}_{2} \mathrm{DCF}(A)$ by dense core plaques that are clearly visualized with thioflavine $S(B)$. Arrows indicate the absence ofDCF-labeled plaques $(A)$ in the same location that contained thioflavine $S$-positive plaques $(B)$. Green fluorescence in $A$ is caused by autofluorescent lipofuscin. Blood vessels used as a site map for reimaging are shown in red. Scale bar, $25 \mu \mathrm{m}$.

after systemic PBN treatment $(287.2 \pm 145.6$; mean $\pm \mathrm{SD} ; n=$ 144 plaques controls vs $163.5 \pm 104.3 ; n=56$ plaques in $\mathrm{PBN}$ treated animals; $p<0.001$; Student's $t$ test). We interpret this result to support the idea that the DCF fluorescence observed without PBN treatment is caused by free radical generation and also to demonstrate that systemic therapy with an antioxidant can reduce plaque-induced free radical generation. We again observed autofluorescent lipofuscin near plaques throughout the brain, seen in Figure $3 A$ in green, but these were not DCFpositive, because control images appeared identical.

The observation that dense core plaques led to oxidation of both probes raised the question of whether this was attributable to the different physicochemical structures of amyloid- $\beta$ and associated molecules or to the effects of activated microglia that frequently associate with dense core plaques (Frautschy et al., 1998). We examined this possibility using an ex vivo, acellular system in which no active microglia were present. In lightly fixed tissue sections from human AD brain and PDAPP mouse brain, both Amplex Red and $\mathrm{H}_{2}$ DCF fluorescently labeled dense core amyloid plaques but did not reveal fluorescence associated with diffuse amyloid- $\beta$. Figure 4 displays human AD tissue after application of Amplex Red. Dense core plaques activated Amplex Red (Fig. 4A), but large areas of diffuse amyloid that did not contain dense core plaques did not activate the probe (Fig. $4 \mathrm{~B}$ ), as assessed by counterstaining with thioflavine $S$ for dense core plaques (Fig. $4 C, D$, respectively) and anti-amyloid- $\beta$ immunohistochemistry for diffuse plaques (Fig. $4 E, F$ ). Interestingly, even within dense core "mature" plaques, the central region that is thioflavine S-positive activated the probe, but the surrounding diffuse amyloid- $\beta$ halo around the dense core did not (Fig. $4 A, C, E)$. We observed a few examples of small deposits positive for Amplex red and 3d6 staining, but negative for thioflavine $S$ (Fig. $4 A, C, E$ ) These may be immature amyloid- $\beta$ deposits capable of oxidative activity, but not yet morphologically recognized by thioflavine S. Chronic imaging experiments may reveal maturation of these deposits into more classically identified plaques. We also tested $\mathrm{H}_{2} \mathrm{DCF}$ in human $\mathrm{AD}$ tissue and obtained results comparable to Amplex Red (data not shown). We performed analogous ex vivo experiments in PDAPP mouse brain tissue. Figure 5 demonstrates that both Amplex Red and DCF associated with dense core plaques (Fig. 5A, $B$, respectively), shown by thioflavine $\mathrm{S}$ labeling (Fig. 5C,D, respectively), but did not associate with diffuse amyloid, shown by immunohistochemistry with anti-amyloid- $\beta$ antibody (Fig. 5E,F). The combined results from 

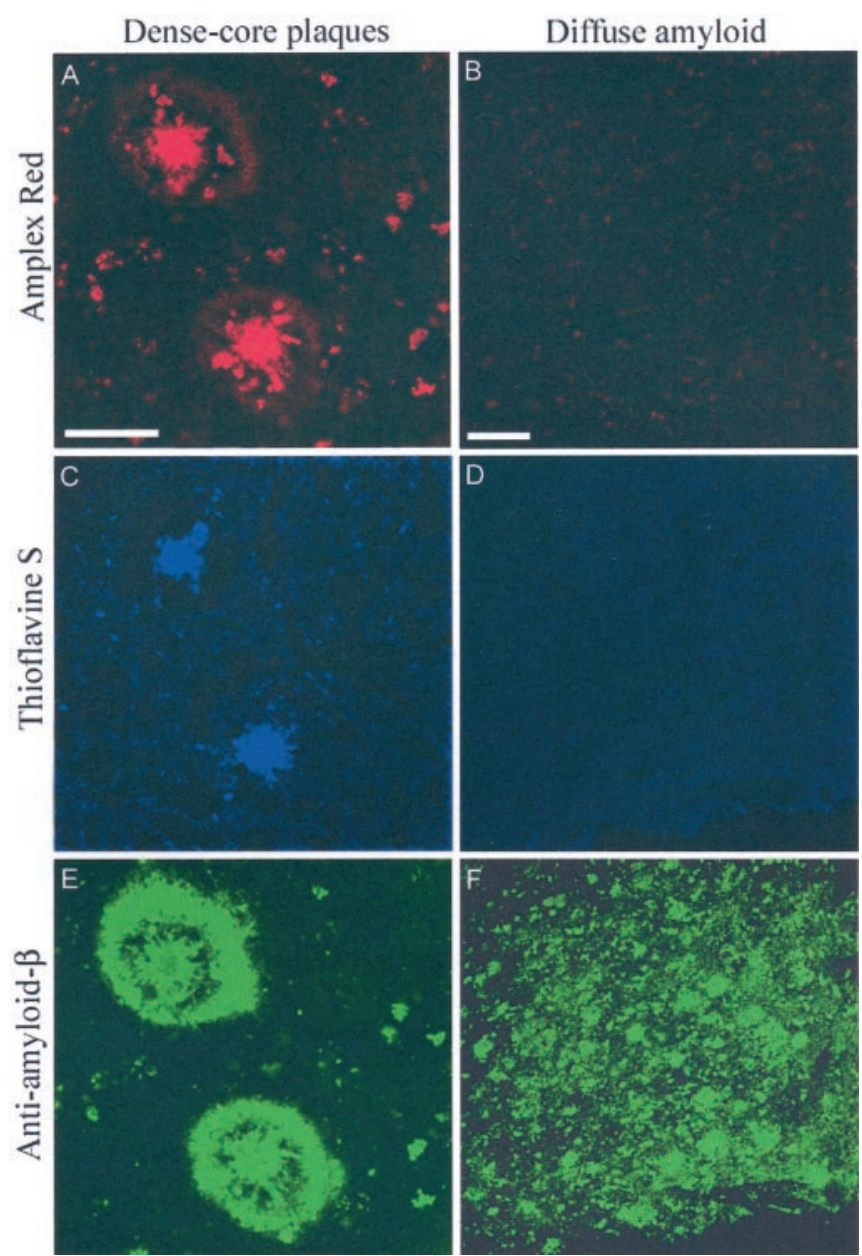

Figure 4. Dense core plaques produce free radicals ex vivo in human AD tissue. Amplex Red was tested in human $A D$ brain tissue containing only dense core plaques $(A, C, E)$ or only diffuse amyloid $(B, D, F)$. Dense core plaques oxidize Amplex Red $(A)$, but diffuse amyloid- $\beta$ does not $(B)$. Thioflavine $S$ staining $(C, D$, respectively) and anti-amyloid- $\beta$ immunohistochemistry $(E, F$, respectively), in the same tissue sections confirm that Amplex Red associates specifically with thioflavine $S$ - positive dense core plaques, but not larger areas of diffuse amyloid- $\beta$ alone. Similar results were seen using $\mathrm{H}_{2} \mathrm{DCF}$ as the free radical indicator (data not shown). Scale bars: $A, C, E, 50 \mu \mathrm{m} ; B, D, F, 100 \mu \mathrm{m}$.

ex vivo experiments in human and mouse tissue suggest that amyloid- $\beta$ itself, and not a cellular-mediated mechanism, is responsible for the oxidative activity associated with dense core plaques. Furthermore, in human tissue, we observed neurofibrillary tangles that bound thioflavine $S$, indicative of a $\beta$-pleated sheet structure, but did not oxidize the free radical probes (data not shown). This observation reinforces that the presence of amyloid- $\beta$, and not simply a $\beta$-pleated sheet conformation, is required for the free radical generation.

In addition, we were able to reduce $\mathrm{H}_{2} \mathrm{DCF}$ oxidation in ex vivo PDAPP mouse tissue by $65 \%$ with pretreatment of the sections with PBN. Sections from 18-month-old mice were incubated with $200 \mu \mathrm{M} \mathrm{H} \mathrm{H}_{2}$ DCF with or without $100 \mu \mathrm{M}$ PBN in PBS for $1 \mathrm{hr}$. The slides were rinsed with PBS and then imaged with multiphoton microscopy. After imaging, the slides were treated with thioflavine $S(0.01 \%$ in PBS) for $20 \mathrm{~min}$, rinsed, and then the same plaque fields were reimaged with multiphoton microscopy. Oxidation of the fluorescent probes was quantified by normalizing the detectable DCF fluorescence in the tissue to subsequent thioflavine $S$ fluorescence for each individual plaque. This approach yielded a ratio of $1.7 \pm 0.5$ for $n=29$ plaques in four
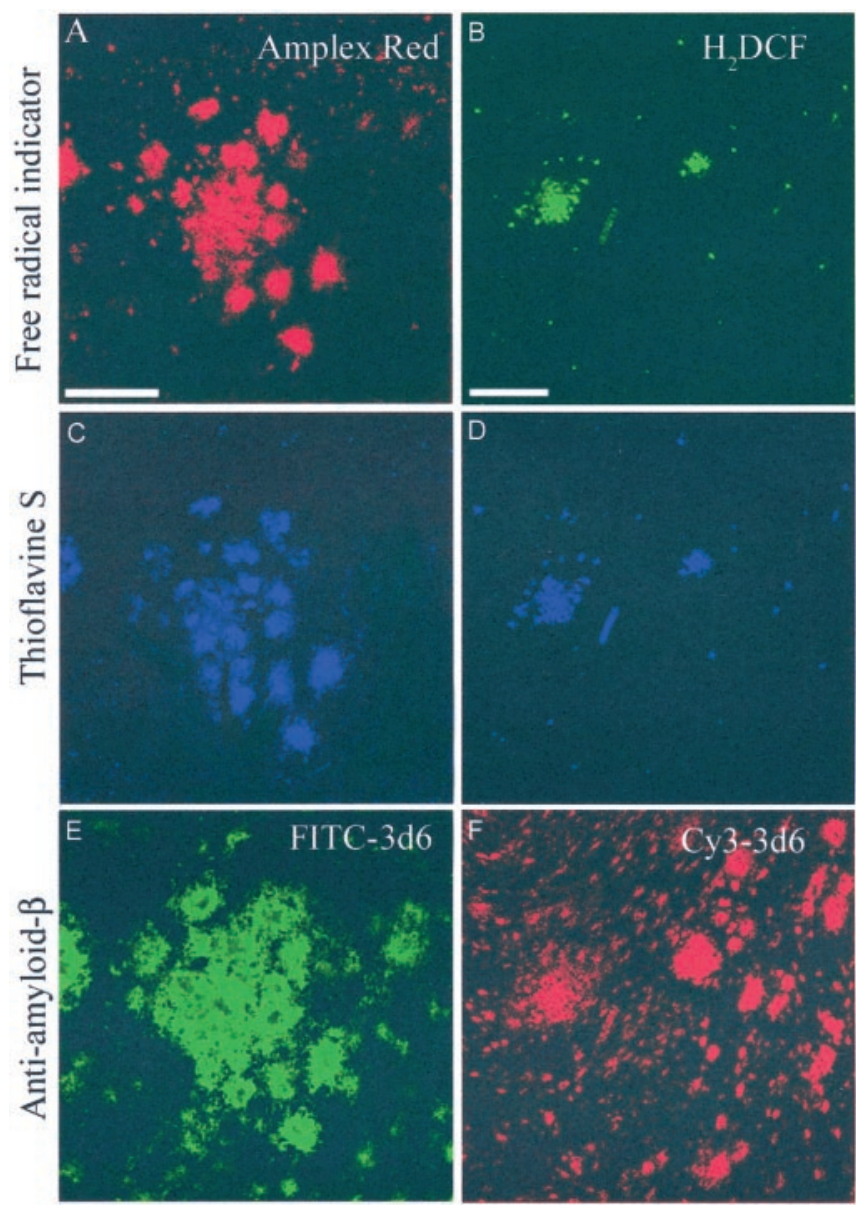

Figure 5. Dense core plaques produce free radicals ex vivo in PDAPP mouse tissue. Similar to human $\mathrm{AD}$ tissue, dense core plaques also oxidize Amplex Red $(A)$ and $\mathrm{H}_{2} \mathrm{DCF}(B)$ in PDAPP mouse brain tissue. Thioflavine $S$ labeling $(C, D$, respectively) and anti-amyloid- $\beta$ immunohistochemistry ( $E, F$, respectively), in the same tissue sections again reveal that dense core plaques, but not diffuse plaques, oxidize the free radical probes. Scale bars: $A, C, E, 50 \mu \mathrm{m} ; B, D, F, 100 \mu \mathrm{m}$.

tissue sections in DCF-alone treated tissue versus $0.6 \pm 0.2$ for $n=17$ plaques in four tissue sections in the presence of the antioxidant PBN ( $p<0.001$; Student's $t$ test).

\section{Discussion}

Because of high energy requirements, high oxygen consumption, and relatively low antioxidant defenses compared with other bodily systems, the CNS is very vulnerable to oxidative stress (Floyd, 1999). The extent to which oxidative damage plays a role in $\mathrm{AD}$ has been difficult to assess directly, however. We now provide a direct observation of amyloid- $\beta$-related oxidative stress in living, transgenic mice and, in analogous ex vivo experiments, in human $\mathrm{AD}$ brain tissue. Two fluorogenic free radical indicators associate with dense core, but not diffuse, plaques. Probe oxidation was prevented in the mice using a systemically administered, well characterized free radical spin trap, PBN (Carney et al., 1991; Socci et al., 1995; Sack et al., 1996; Miyajima and Kotake, 1997). These data show directly that a subset of amyloid- $\beta$ containing senile plaques are a source of free radicals in vivo, rather than relying on indirect measures of oxidative damage, and the ability to neutralize these highly reactive and damaging molecules using antioxidant therapy shows promise for therapeutic use in Alzheimer's disease.

The significance of these results is twofold. First, the ability to directly monitor amyloid plaques and their association with free 
radical production focuses attention on amyloid- $\beta$-induced oxidative damage in the brains of PDAPP and Tg2576 transgenic mice and in AD. The toxicity of amyloid- $\beta$ has been clearly shown in vitro. When placed in physiological solution, amyloid- $\beta$ precipitates into fibrils and generates free radicals (Hensley et al., 1994). Amyloid- $\beta$ fragments have been shown to induce free radical production in cell culture (Behl et al., 1994) and have neurotoxic effects (Le et al., 1995). Recent studies have suggested that, because free radicals can promote protein cross-linking, they mediate amyloid fibril formation influenced by the free radical-producing amyloid peptide itself (Mattson, 1995). Thus, a vicious cycle may result involving APP and amyloid- $\beta$ processing that is further enhanced by oxidative stress (Yan et al., 1995).

Despite this in vitro data, evidence of amyloid- $\beta$ toxicity in vivo is conflicting. Some studies of amyloid- $\beta$ in transgenic mice suggest limited direct toxicity in which global neuronal loss is not associated with age-dependent amyloid- $\beta$ deposition (Takeuchi et al., 2000). We have recently found, however, that discrete areas of neuronal loss can be detected in the local areas corresponding to thioflavine S-positive amyloid- $\beta$ plaques, although these compact plaques represent only a minority of all the amyloid- $\beta$ deposits (Urbanc et al., 2002). Our current data demonstrate directly, for the first time, the presence of free radicals generated by amyloid- $\beta$ in vivo, as well as ex vivo, in human $\mathrm{AD}$ brain tissue. This free radical generation corresponds to the same morphological subset of plaques associated with focal neuronal loss, suggesting that the conformation of amyloid- $\beta$ in thioflavine $S$ plaques is associated both with local neurotoxicity and with local free radical generation. Our data also provide a pathophysiological correlate to the observations that there is diminished density of dendrites and of synaptophysin within thioflavine S-positive, but not diffuse plaques (Masliah et al., 1990; Knowles et al., 1998; Knowles et al., 1999). Further support for our findings is the recent evidence that an antibody detecting oxidized amyloid- $\beta$ labels dense core plaques to a much greater extent than diffuse amyloid in human $\mathrm{AD}$ and Down syndrome tissue sections (Head et al., 2001), and that protein and lipid oxidative stress markers are associated with thioflavine $S$ plaques in PS/APP mice (Matsuoka et al., 2001). Taken together, these data provide compelling evidence that densely aggregated amyloid- $\beta$ is a source of free radicals in both transgenic models of $\mathrm{AD}$ and in $\mathrm{AD}$ itself. Our observation that dense core plaques are robustly and rapidly detected by oxidized DCF and Amplex Red does not rule out the possibility that diffuse amyloid deposits, or even oligomeric forms of amyloid- $\beta$, could be a low-level oxidative source.

Second, our results are significant because of the potential of our system to test the effectiveness of therapies targeting amyloid- $\beta$ and its capacity to generate free radicals in the brains of living $\mathrm{AD}$ models and in $\mathrm{AD}$ tissue samples. Many in vitro studies have found that both biological and synthetic antioxidants provide protection against the neurotoxic effects of supraphysiological doses of amyloid- $\beta$. Vitamin E protects cultured neuroblastoma cells (Behl et al., 1992) and rat hippocampal neurons (Goodman and Mattson, 1994; Keller et al., 1997) from amyloid- $\beta$ neurotoxicity. Other antioxidants and spin traps that protect cells in culture from the neurotoxic effects of amyloid- $\beta$ include catalase (Behl et al., 1994), propyl gallate, PBN, nordihydroguariaretic acid, EUK-8, and glutathione (Behl et al., 1994; Goodman et al., 1994; Mark et al., 1995; Bruce et al., 1996; Zhou et al., 1996). We now extend these observations to the intact brain: we were able to reduce the oxidation of $\mathrm{H}_{2} \mathrm{DCF}$ by plaques in vivo using the free radical spin trap PBN. Several clinical studies indicate slowed progression of AD dementia in patients taking antioxidants (Mattson et al., 1997; Sano et al., 1997; Morris et al., 1998). We speculate that part of their efficacy in slowing the rate of progression of $\mathrm{AD}$ dementia may be by decreasing plaqueinduced free radical damage. In addition, a recent study showing that transgenic mice treated with the curry spice derivative curcumin, a potent antioxidant, exhibited decreased plaque burdens and indicators of oxidative stress, supporting this speculation (Lim et al., 2001). The observations that antioxidants appear to have a protective effect both in transgenic models and in Alzheimer's disease support the idea that plaque-mediated free radical production is important.

Our data highlight the potential to use both an ex vivo and an in vivo system to develop and screen antioxidant treatments in models of AD. Moreover, free radical-mediated mechanisms have been implicated in ischemia, Parkinson's disease, amyotrophic lateral sclerosis, and head trauma. Our current technology allows imaging of free radical generation in vivo, in real time. Thus, multiphoton imaging using agents sensitive to free radicals provides a sensitive biomarker for the efficacy of antioxidant therapies for senile plaques as well as for other pathological conditions.

\section{References}

Bacskai BJ, Kajdasz ST, Christie RH, Carter C, Games D, Seubert P, Schenk D, Hyman BT (2001) Imaging of amyloid-beta deposits in brains of living mice permits direct observation of clearance of plaques with immunotherapy. Nat Med 7:369-372.

Bacskai BJ, Kajdasz ST, McLellan ME, Games D, Seubert P, Schenk D, Hyman BT (2002) Non-Fc-mediated mechanisms are involved in clearance of amyloid-beta in vivo by immunotherapy. J Neurosci 22:7873-7878.

Behl C, Davis J, Cole GM, Schubert D (1992) Vitamin E protects nerve cells from amyloid beta protein toxicity. Biochem Biophys Res Commun 186:944-950.

Behl C, Davis JB, Lesley R, Schubert D (1994) Hydrogen peroxide mediates amyloid beta protein toxicity. Cell 77:817-827.

Bruce AJ, Malfroy B, Baudry M (1996) beta-Amyloid toxicity in organotypic hippocampal cultures: protection by EUK-8, a synthetic catalytic free radical scavenger. Proc Natl Acad Sci USA 93:2312-2316.

Bush AI, Lynch T, Cherny RA, Atwood CS, Goldstein LE, Moir RD, Li Q-X, Cabelli DE, Multhaup G, Masters CL, Tanzi RE, Huang X (1999) Alzheimer A-beta functions as a superoxide antioxidant in vitro and in vivo. Soc Neurosci Abstr 25:14.

Carney JM, Starke-Reed PE, Oliver CN, Landum RW, Cheng MS, Wu JF, Floyd RA (1991) Reversal of age-related increase in brain protein oxidation, decrease in enzyme activity, and loss in temporal and spatial memory by chronic administration of the spin-trapping compound $N$-tert-butylalpha-phenylnitrone. Proc Natl Acad Sci USA 88:3633-3636.

Christie R, Kimchi E, Kajdasz S, Bacskai B, Hyman BT (2001) Multiphoton microscopy and amyloid angiopathy. Amyloid [Suppl 1] 8:48-50.

Colton CA, Snell J, Chernyshev O, Gilbert DL (1994) Induction of superoxide anion and nitric oxide production in cultured microglia. Ann NY Acad Sci 738:54-63.

Floyd RA (1999) Antioxidants, oxidative stress, and degenerative neurological disorders. Proc Soc Exp Biol Med 222:236-245.

Frautschy SA, Yang F, Irrizarry M, Hyman B, Saido TC, Hsiao K, Cole GM (1998) Microglial response to amyloid plaques in APPsw transgenic mice. Am J Pathol 152:307-317.

Games D, Adams D, Alessandrini R, Barbour R, Berthelette P, Blackwell C, Carr T, Clemens J, Donaldson T, Gillespie F, Guido T, Hagoplan S, Johnson-Wood K, Kahn K, Lee M, Leibowitz P, Lieberburg I, Little S, Masliah E, McConlogue L, et al. (1995) Alzheimer-type neuropathology in transgenic mice overexpressing V717F beta-amyloid precursor protein. Nature 373:523-527.

Good PF, Werner P, Hsu A, Olanow CW, Perl DP (1996) Evidence of neuronal oxidative damage in Alzheimer's disease. Am J Pathol 149:21-28.

Goodman Y, Mattson MP (1994) Secreted forms of beta-amyloid precursor protein protect hippocampal neurons against amyloid beta-peptideinduced oxidative injury. Exp Neurol 128:1-12.

Goodman Y, Steiner MR, Steiner SM, Mattson MP (1994) Nordihydroguai- 
aretic acid protects hippocampal neurons against amyloid beta-peptide toxicity, and attenuates free radical and calcium accumulation. Brain Res 654:171-176.

Head E, Garzon-Rodriguez W, Johnson JK, Lott IT, Cotman CW, Glabe C (2001) Oxidation of Abeta and plaque biogenesis in Alzheimer's disease and Down syndrome. Neurobiol Dis 8:792-806.

Hensley K, Carney JM, Mattson MP, Aksenova M, Harris M, Wu JF, Floyd RA, Butterfield DA (1994) A model for beta-amyloid aggregation and neurotoxicity based on free radical generation by the peptide: relevance to Alzheimer disease. Proc Natl Acad Sci USA 91:3270-3274.

Hensley K, Hall N, Subramaniam R, Cole P, Harris M, Aksenov M, Aksenova M, Gabbita SP, Wu JF, Carney JM, et al (1995) Brain regional correspondence between Alzheimer's disease histopathology and biomarkers of protein oxidation. J Neurochem 65:2146-2156.

Hsiao K, Chapman P, Nilsen S, Eckman C, Harigaya Y, Younkin S, Yang F, Cole G (1996) Correlative memory deficits, Abeta elevation, and amyloid plaques in transgenic mice. Science 274:99-102.

Keller JN, Pang Z, Geddes JW, Begley JG, Germeyer A, Waeg G, Mattson MP (1997) Impairment of glucose and glutamate transport and induction of mitochondrial oxidative stress and dysfunction in synaptosomes by amyloid beta-peptide: role of the lipid peroxidation product 4-hydroxynonenal. J Neurochem 69:273-284.

Kiprianova I, Schwab S, Fandrey J, Spranger M (1997) Suppression of the oxidative burst in murine microglia by nitric oxide. Neurosci Lett 226:75-78.

Knowles RB, Gomez-Isla T, Hyman BT (1998) Abeta associated neuropil changes: correlation with neuronal loss and dementia. J Neuropathol Exp Neurol 57:1122-1130.

Knowles RB, Wyart C, Buldyrev SV, Cruz L, Urbanc B, Hasselmo ME, Stanley HE, Hyman BT (1999) Plaque-induced neurite abnormalities: implications for disruption of neural networks in Alzheimer's disease. Proc Natl Acad Sci USA 96:5274-5279.

Le WD, Colom LV, Xie WJ, Smith RG, Alexianu M, Appel SH (1995) Cell death induced by beta-amyloid 1-40 in MES 23.5 hybrid clone: the role of nitric oxide and NMDA-gated channel activation leading to apoptosis. Brain Res 686:49-60.

LeBel CP, Ischiropoulos H, Bondy SC (1992) Evaluation of the probe 2', $7^{\prime}$-dichlorofluorescin as an indicator of reactive oxygen species formation and oxidative stress. Chem Res Toxicol 5:227-231.

Leutner S, Czech C, Schindowski K, Touchet N, Eckert A, Muller WE (2000) Reduced antioxidant enzyme activity in brains of mice transgenic for human presenilin-1 with single or multiple mutations. Neurosci Lett 292:87-90.

Lim GP, Chu T, Yang F, Beech W, Frautschy SA, Cole GM (2001) The curry spice curcumin reduces oxidative damage and amyloid pathology in an Alzheimer transgenic mouse. J Neurosci 21:8370-8377.

Mark RJ, Hensley K, Butterfield DA, Mattson MP (1995) Amyloid betapeptide impairs ion-motive ATPase activities: evidence for a role in loss of neuronal $\mathrm{Ca}^{2+}$ homeostasis and cell death. J Neurosci 15:6239-6249.

Mark RJ, Pang Z, Geddes JW, Uchida K, Mattson MP (1997) Amyloid betapeptide impairs glucose transport in hippocampal and cortical neurons: involvement of membrane lipid peroxidation. J Neurosci 17:1046-1054.

Masliah E, Terry RD, Mallory M, Alford M, Hansen LA (1990) Diffuse plaques do not accentuate synapse loss in Alzheimer's disease. Am J Pathol 137:1293-1297.

Mathis CA, Bacskai BJ, Kajdasz ST, McLellan ME, Frosch MP, Hyman BT, Holt DP, Wang Y, Huang GF, Debnath ML, Klunk WE (2002) A lipophilic thioflavin-T derivative for positron emission tomography (PET) imaging of amyloid in brain. Bioorg Med Chem Lett 12:295-298.

Matsuoka Y, Picciano M, La Francois J, Duff K (2001) Fibrillar-amyloid evokes oxidative damage in a transgenic mouse model of Alzheimer's disease. Neuroscience 104:609-613.

Mattson MP (1995) Untangling the pathophysiochemistry of beta-amyloid. Nat Struct Biol 2:926-928.

Mattson MP, Goodman Y (1995) Different amyloidogenic peptides share a similar mechanism of neurotoxicity involving reactive oxygen species and calcium. Brain Res 676:219-224.

Mattson MP, Begley JG, Mark RJ, Furukawa K (1997) Abeta25-35 induces rapid lysis of red blood cells: contrast with Abeta1-42 and examination of underlying mechanisms. Brain Res 771:147-153.

Miyajima T, Kotake Y (1997) Optimal time and dosage of phenyl N-tert- butyl nitrone (PBN) for the inhibition of nitric oxide synthase induction in mice. Free Radic Biol Med 22:463-470.

Montine KS, Olson SJ, Amarnath V, Whetsell Jr WO, Graham DG, Montine TJ (1997) Immunohistochemical detection of 4-hydroxy-2-nonenal adducts in Alzheimer's disease is associated with inheritance of APOE4. Am J Pathol 150:437-443.

Morris MC, Beckett LA, Scherr PA, Hebert LE, Bennett DA, Field TS, Evans DA (1998) Vitamin E and vitamin C supplement use and risk of incident Alzheimer disease. Alzheimer Dis Assoc Disord 12:121-126.

Newell KL, Hyman BT, Growdon JH, Hedley-Whyte ET (1999) Application of the National Institute on Aging (NIA)-Reagan Institute criteria for the neuropathological diagnosis of Alzheimer disease. J Neuropathol Exp Neurol 58:1147-1155.

Nunomura A, Perry G, Pappolla MA, Friedland RP, Hirai K, Chiba S, Smith MA (2000) Neuronal oxidative stress precedes amyloid-beta deposition in Down syndrome. J Neuropathol Exp Neurol 59:1011-1017.

Pappolla MA, Chyan YJ, Omar RA, Hsiao K, Perry G, Smith MA, Bozner P (1998) Evidence of oxidative stress and in vivo neurotoxicity of betaamyloid in a transgenic mouse model of Alzheimer's disease: a chronic oxidative paradigm for testing antioxidant therapies in vivo. Am J Pathol 152:871-877.

Pratico D, Uryu K, Leight S, Trojanoswki JQ, Lee VM (2001) Increased lipid peroxidation precedes amyloid plaque formation in an animal model of Alzheimer amyloidosis. J Neurosci 21:4183-4187.

Sack CA, Socci DJ, Crandall BM, Arendash GW (1996) Antioxidant treatment with phenyl-alpha-tert-butyl nitrone (PBN) improves the cognitive performance and survival of aging rats. Neurosci Lett 205:181-184.

Sano M, Ernesto C, Thomas RG, Klauber MR, Schafer K, Grundman M, Woodbury P, Growdon J, Cotman CW, Pfeiffer E, Schneider LS, Thal LJ (1997) A controlled trial of selegiline, alpha-tocopherol, or both as treatment for Alzheimer's disease. The Alzheimer's Disease Cooperative Study. N Engl J Med 336:1216-1222.

Sayre LM, Zelasko DA, Harris PL, Perry G, Salomon RG, Smith MA (1997) 4-Hydroxynonenal-derived advanced lipid peroxidation end products are increased in Alzheimer's disease. J Neurochem 68:2092-2097.

Smith MA, Perry G, Richey PL, Sayre LM, Anderson VE, Beal MF, Kowall N (1996) Oxidative damage in Alzheimer's. Nature 382:120-121.

Smith MA, Richey Harris PL, Sayre LM, Beckman JS, Perry G (1997) Widespread peroxynitrite-mediated damage in Alzheimer's disease. J Neurosci 17:2653-2657.

Socci DJ, Crandall BM, Arendash GW (1995) Chronic antioxidant treatment improves the cognitive performance of aged rats. Brain Res 693:88-94.

Takeuchi A, Irizarry M, Duff K, Saido T, Hsiao Ashe K, Hasegawa M, Mann D, Hyman B, Iwatsubo T (2000) Age-related amyloid beta deposition in transgenic mice overexpressing both Alzheimer mutant presenilin 1 and amyloid beta precursor protein Swedish mutant is not associated with global neuronal loss. Am J Pathol 157:331-339.

Urbanc B, Cruz L, Le R, Sanders J, Ashe KH, Duff K, Stanley HE, Irizarry MC, Hyman BT (2002) Neurotoxic effects of thioflavin S-positive amyloid deposits in transgenic mice and Alzheimer's disease. Proc Natl Acad Sci USA 99:13990-13995.

Wong A, Luth HJ, Deuther-Conrad W, Dukic-Stefanovic S, GasicMilenkovic J, Arendt T, Munch G (2001) Advanced glycation endproducts co-localize with inducible nitric oxide synthase in Alzheimer's disease. Brain Res 920:32-40.

Yan SD, Yan SF, Chen X, Fu J, Chen M, Kuppusamy P, Smith MA, Perry G, Godman GC, Nawroth P, Zweier JL, Stern D (1995) Non-enzymatically glycated tau in Alzheimer's disease induces neuronal oxidant stress resulting in cytokine gene expression and release of amyloid beta-peptide. Nat Med 1:693-699.

Zhou M, Diwu Z, Panchuk-Voloshina N, Haugland RP (1997) A stable nonfluorescent derivative of resorufin for the fluorometric determination of trace hydrogen peroxide: applications in detecting the activity of phagocyte NADPH oxidase and other oxidases. Anal Biochem 253:162-168.

Zhou Y, Gopalakrishnan V, Richardson JS (1996) Actions of neurotoxic beta-amyloid on calcium homeostasis and viability of PC12 cells are blocked by antioxidants but not by calcium channel antagonists. J Neurochem 67:1419-1425. 